\title{
STATE OF STRENGTH IN MASSIVE CONCRETE STRUCTURE SUBJECTED TO NON-MECHANICAL LOADS
}

\author{
DARIUSZ ŁYDŻBA, MACIEJ SOBÓTKA \\ Wrocław University of Technology, Faculty of Civil Engineering, \\ Wrocław, Poland, e-mail: dariusz.lydzba@pwr.edu.pl, maciej.sobotka@pwr.edu.pl
}

\begin{abstract}
The paper deals with an impact of non-mechanical loads on the state of strength in massive concrete hydraulic structures. An example of hydroelectric plant subjected to the effect of water temperature annual fluctuation is considered. Numerical analysis of transient thermal-elasticity problem was performed. After determining the temperature distributions within the domain, the Duhamel-Neumann set of constitutive equations was employed to evaluate fields of mechanical quantities: displacement, strain and stress. The failure criterion proposed by Pietruszczak was adopted in assessing whether the load induces exceeding of strength of concrete within the structure volume. The primary finding is that the temperature effect can lead to damage of concrete in draft tubes and spirals, especially in winter months.
\end{abstract}

Key words: non-mechanical load, massive concrete structure, hydro power plant, temperature impact

\section{INTRODUCTION}

Non-mechanical loads play the key role in the state of strength of massive concrete structures [1][3]. In the case of hydraulic structures, the most notable non-mechanical loads include the annual changes in temperature of the water in the river, drying shrinkage of the concrete during the construction as well as hydration heat [4]. In addition, chemical causes like alkali-aggregate reaction (AAR) affect the durability and serviceability of hydraulic structures by the effect of deterioration of concrete characteristics [1], [2], [5]. As the evidence suggests, one of the major non-mechanical loads is an annual fluctuation in temperature of water [3], [6].

An impact of annual changes in water temperature on the massive concrete elements has already been discussed in former work of the authors [6]. The temperature distribution in a $6 \mathrm{~m}$ thick concrete wall exposed to contact with river water was investigated. The obtained results indicate that for two time points in the year, when the concrete takes about minimum and maximum temperature, there is no significant temperature gradient within the concrete volume. Then, adopting the assumption that the temperature is uniform over all concrete elements, a stress distribution within the hydro power plant (HPP) was computed. The state of strength was assessed based on the Drucker-Prager criterion. The results showed that changes in temperature could cause damage to concrete elements. This paper is an extension of aforementioned. A transient thermo-elasticity problem is considered. Hereby, the approach allows analyzing the state of strength in the structure at any time point over the year. Moreover, the exact temperature distributions make the results of mechanical analysis more reliable. Furthermore, more adequate strength criterion is employed in assessing the state of strength in concrete elements of the HPP, i.e., failure locus proposed by Pietruszczak et al. [12] is adopted.

The paper is organized as follows. The next section discusses the annual temperature course of water in the river and the way it is accounted for in further analysis. The main issue addressed in the paper comprises numerical simulations. The transient thermo-elasticity problem concerning a block of HPP example located on the Vistula River is under consideration. Providing an assumption that the dependence of mechanical properties on thermal state of material is negligible, the transient thermoelasticity problem can be solved as uncoupled [7], [8]. Therefore, the first stage of the analyses involves the problem of transient heat flow in the concrete structure of the power station and extracted region of subsoil. The second stage incorporates temperature distributions obtained in compu- 
tations concerning mechanical fields, i.e., displacement distribution and consequently stress. The Duhamel-Neumann relations are used as a constitutive set of equations, e.g., [7], [8]. Finally, the state of the structure is assessed in view of concrete strength.

\section{ANNUAL FLUCTUATION IN WATER TEMPERATURE}

The impact of annual fluctuation in water temperature is considered as non-mechanical load of primary importance in this study. The course of the fluctuation in temperature of water in the Vistula River is based on the measurements conducted in the HPP. The evidence covering three years of measurements has already been reported by Łydżba et al. [6]. The authors have also proposed sine function approximation. The temperature course as well as the function approximation is shown in Fig. 1.

As the evidence indicates (black plot in Fig. 1) the temperature of water in the river fluctuates between $1.0{ }^{\circ} \mathrm{C}$ in winter and $20{ }^{\circ} \mathrm{C}$ in summer. That fact is taken as an assumption for constituting the function approximation. Therefore, the variation of water tem- perature over time can be approximated by the following equation

$$
T_{w}=10.5+9.5 \sin \left(\frac{2 \pi}{t_{\text {year }}} t\right)
$$

where $T_{w}$ denotes water temperature, $t_{\text {year }}$ is the period of one year and $t$ denotes the time. Note that the initial time point $(t=0)$ refers to the second half of April, when the value of temperature takes an annual average, equal to $10.5^{\circ} \mathrm{C}$ and the rate of temperature increase reaches maximum.

\section{NUMERICAL SIMULATIONS}

In order to verify the influence of temperature changes on a block of hydroelectric plant numerical calculations were carried out using FEM. FlexPDE software was used to solve a series of initial boundary value problems. The geometrical model consists of one block of hydroelectric plant and extracted region of subsoil. The model comprises 142535 second order tetrahedral elements and 235241 nodes. An outline of the geometrical model of the HPP with the FE grid is provided in Fig. 2.

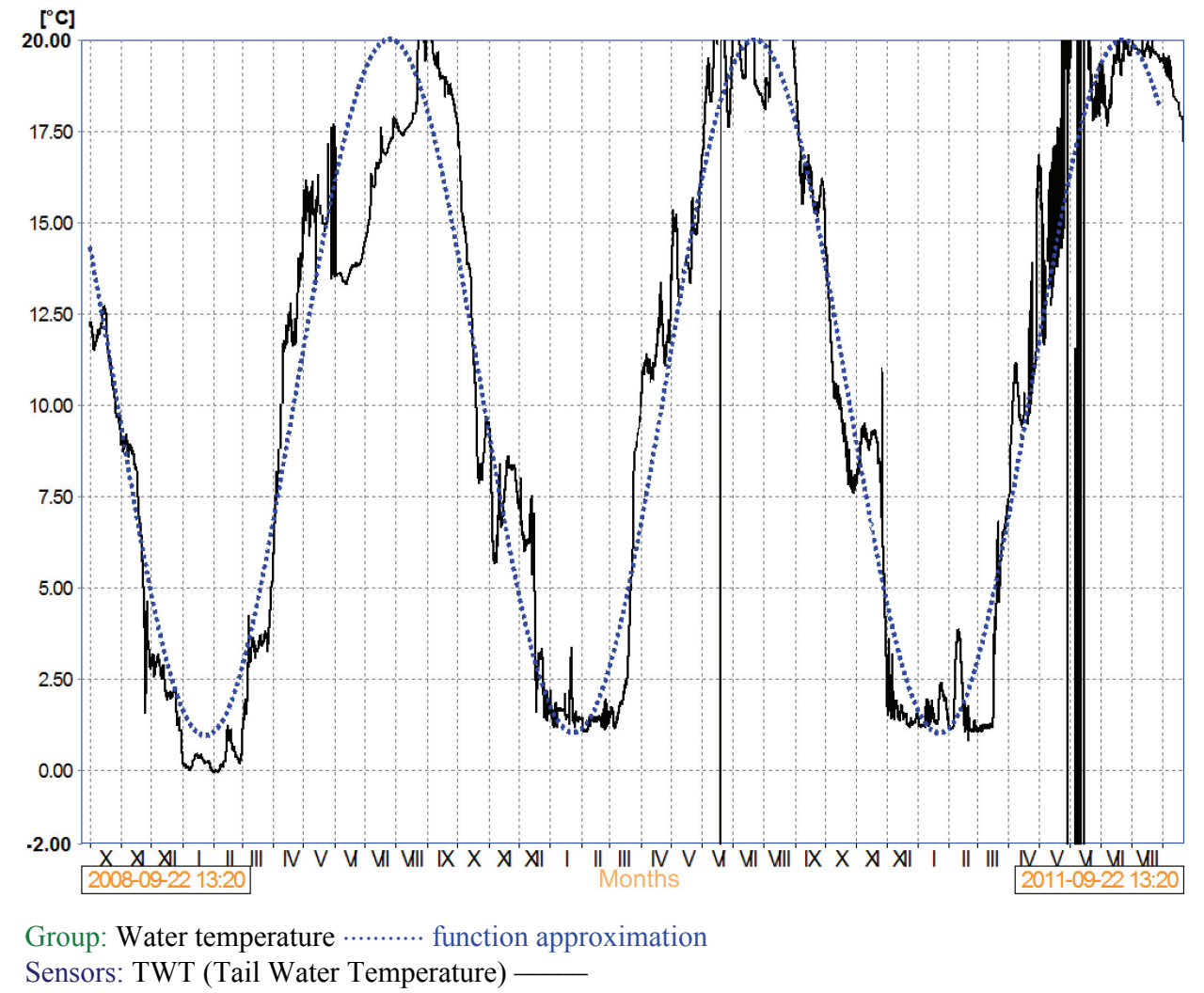

Fig. 1. Measurements of temperature conducted in the HPP and the fitting function 


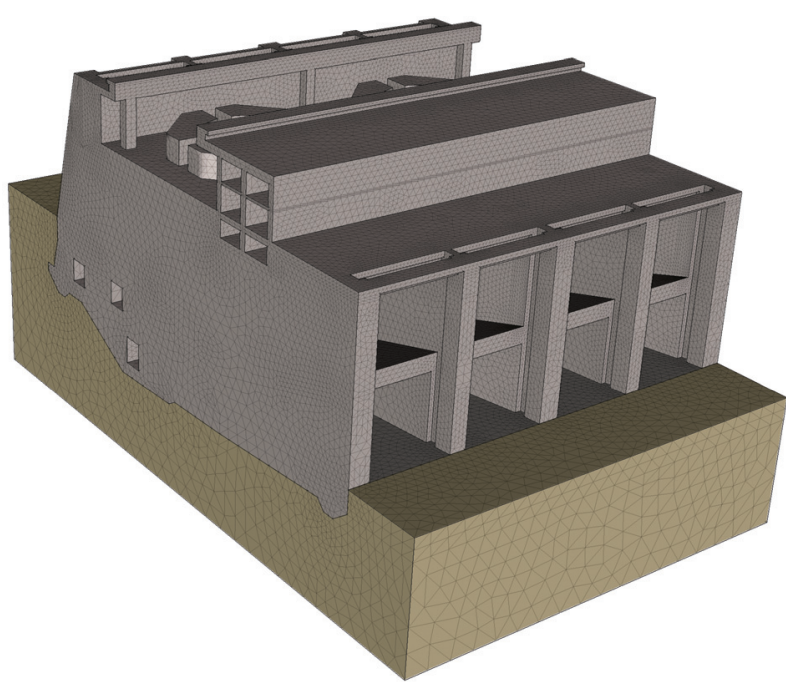

Fig. 2. An outline of the geometrical model of the HPP

The HPP being considered was erected in the 1960 s as a massive concrete structure. It consists of 3 blocks separated by expansion joints. Each block has two generators installed. In this particular work a single block is considered, namely the middle one. The width of the block is about $50 \mathrm{~m}$; the size along the current of the river is about $60 \mathrm{~m}$. The subsoil region extent reaches $10 \mathrm{~m}$ below the base of the structure.

\subsection{TRANSIENT HEAT FLOW ANALYSIS}

A series of numerical calculations of transient heat flow within the HPP and the subsoil were performed. The following equation governs the heat transfer:

$$
\operatorname{div}\left(-\frac{k}{c \rho} \operatorname{grad}(T)\right)+\frac{\partial T}{\partial t}=0
$$

where $k$ - thermal conductivity, $c$ - specific heat capacity, $\rho$ - density, $T$ - temperature and $t$ - time. The values of constants adopted for calculations are: $k_{c}=0.0017 \mathrm{~kW} /\left(\mathrm{m}^{\circ}{ }^{\circ} \mathrm{C}\right)$ for concrete and $k_{s}=$ $0.0004 \mathrm{~kW} /\left(\mathrm{m} \cdot{ }^{\circ} \mathrm{C}\right)$ for the soil, $c_{c}=850 \mathrm{~kJ} /\left(\mathrm{kg}{ }^{\circ} \mathrm{C}\right)$ and $c_{s}=800 \mathrm{~kJ} /\left(\mathrm{kg}{ }^{\circ} \mathrm{C}\right), \rho_{c}=2.5 \mathrm{t} / \mathrm{m}^{3}, \rho_{s}=2.0 \mathrm{t} / \mathrm{m}^{3}$. The material constants adopted above correspond to the typical values for concrete and saturated sand.

Boundary conditions are as follows, i.e.:

- fixed temperature equal to $10.5{ }^{\circ} \mathrm{C}$ at the bottom surface of soil region (average temperature of the soil at that depth);

- fixed value of temperature equal to $20.0{ }^{\circ} \mathrm{C}$ at internal surfaces of halls, offices, inspection galleries, etc.;
- zero heat flux through the surfaces of truncation planes of subsoil as well as expansion joints (consequence of quasi-symmetry of the structure with respect to the expansion joint planes);

- zero heat flux at external surfaces of machine halls and offices due to their external thermal insulation.

The boundary conditions are schematically shown in Fig. 3.

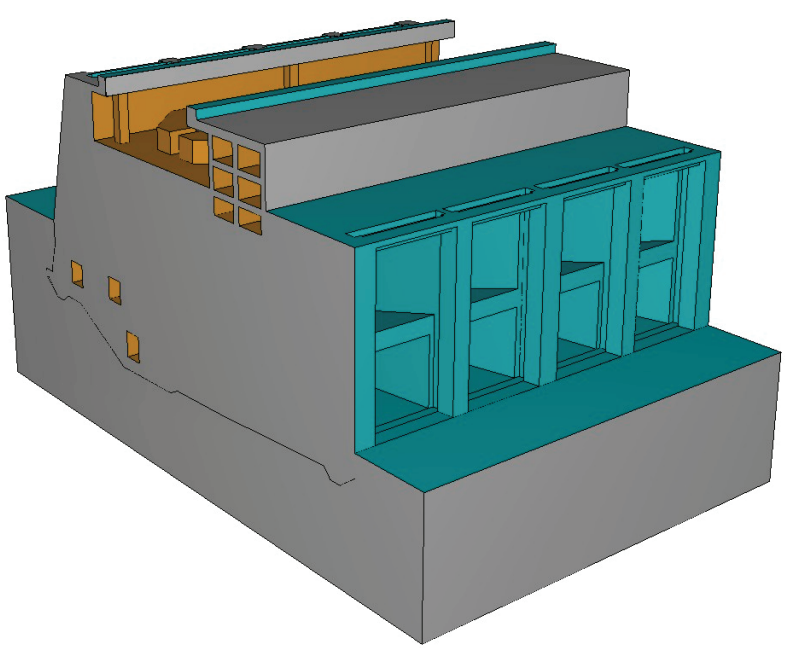

Fig. 3. The boundary conditions in heat transfer analysis - axonometric view of HPP. Blue - fixed temperature of the water in river, according to formula (1), orange - temperature in internal surfaces equal to $20^{\circ} \mathrm{C}$, gray - zero flux through the surface $(\vec{q} \cdot \vec{n}=0)$

The initial condition is the uniform temperature over the HPP and the soil, equal to average year temperature of the water in the river. The calculation involves 5 years' course. The authors present a numerical example that indicates that in this type of the problem the initial condition effect fades after about one or two years [6]. Therefore, the assumption is taken: the initial condition impact in the fifth calculation year is of negligible importance. Then, further consideration reflects on a year, the fifth one.

Results of the computations, i.e., temperature distributions at chosen time points of the year are presented in Figs. 4-7. To show more details, the cross-sections of the draft tubes are presented on the plots. Figure 4 refers to the second half of April when the temperature of water takes the average value and has the maximum increase rate. Figure 5 refers to July, when the temperature of water takes the peak maximum value, Fig. 6 to October and Fig. 7 to January, when the temperature is the lowest. 

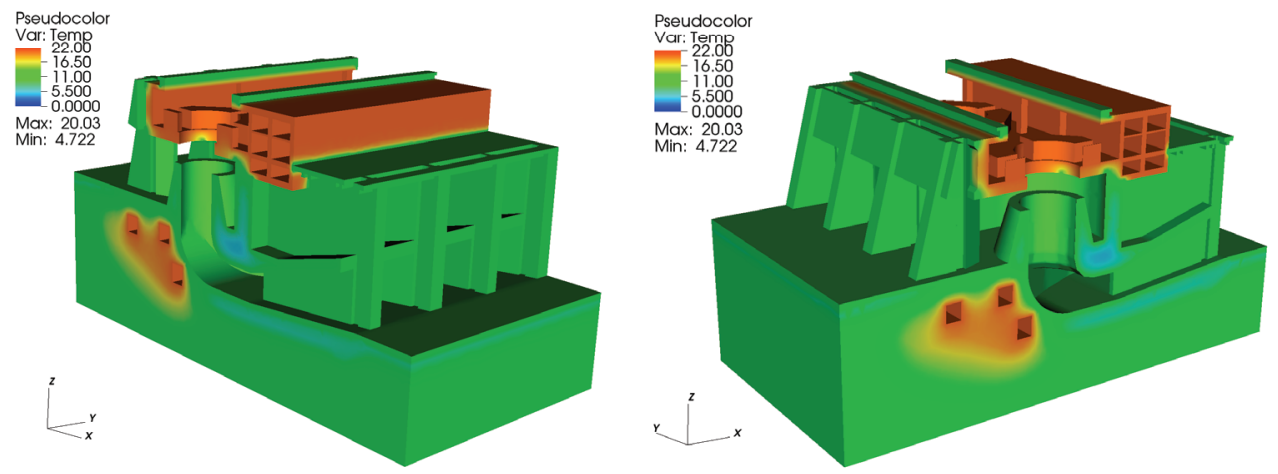

Fig. 4. The temperature distribution in April
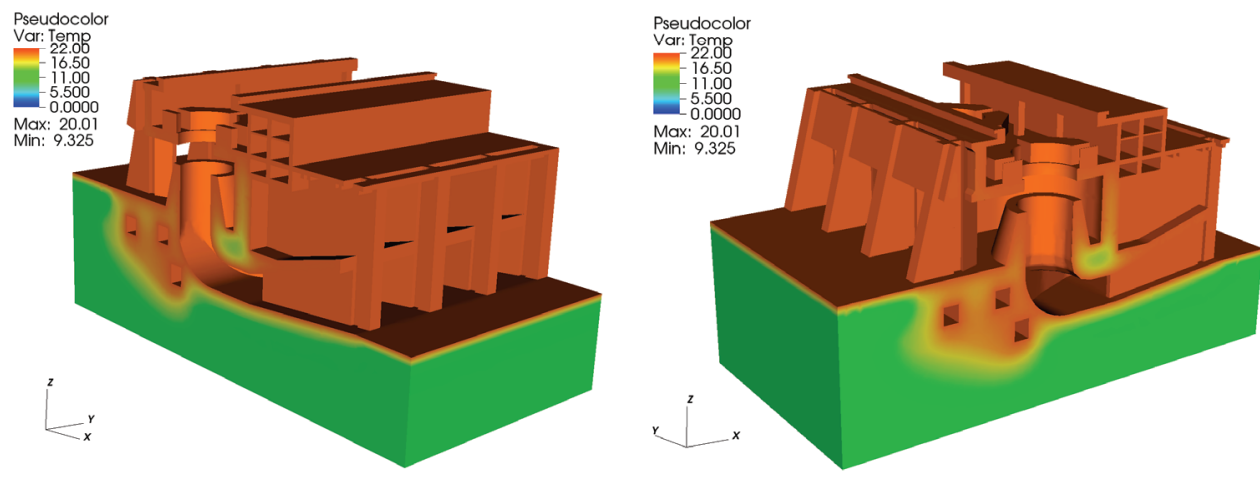

Fig. 5. The temperature distribution in July
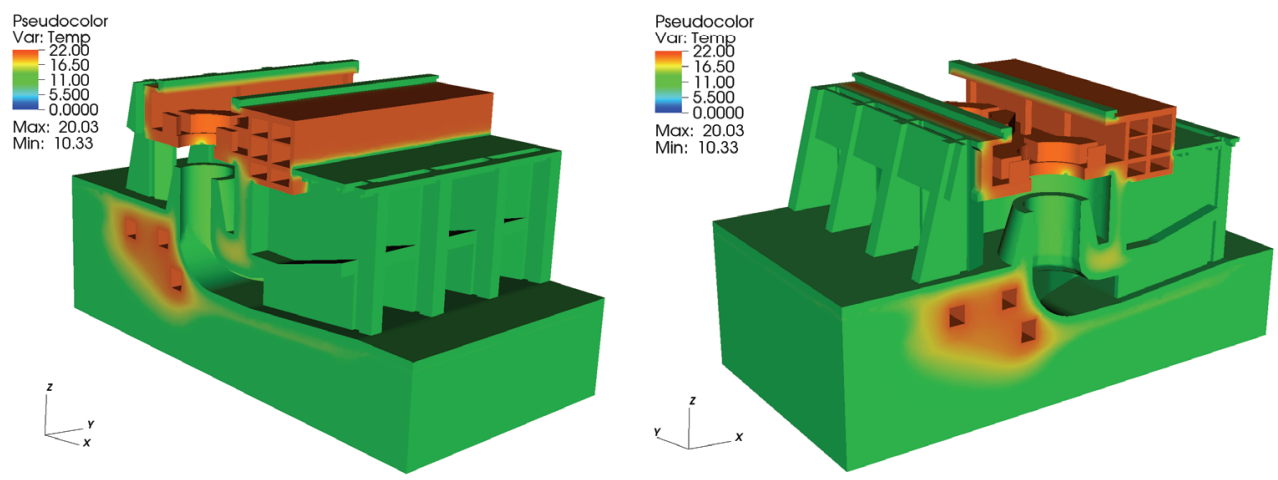

Fig. 6. The temperature distribution in October
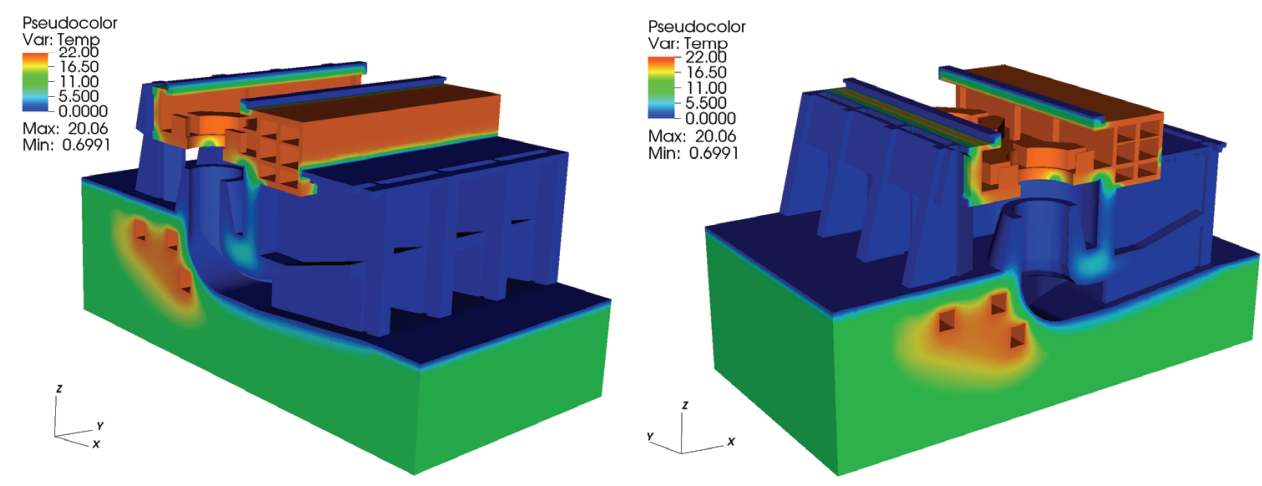

Fig. 7. The temperature distribution in January 


\subsection{ANALYSIS OF STRESS DISTRIBUTION WITHIN THE STRUCTURE}

Calculations concerning displacement and stress fields cover full year course, month by month. The stress distributions at chosen time points were obtained by incorporation of the temperature distribution determined from transient heat flow analysis. The Duhamel-Neumann set of constitutive equations is employed. For isotropic case, it can be expressed as

$$
\sigma_{i j}=2 G \varepsilon_{i j}+\delta_{i j} \lambda \varepsilon_{k k}-\alpha \delta_{i j}(2 G+3 \lambda)\left(T-T_{0}\right)
$$

where $\sigma_{i j}$ - stress tensor, $\varepsilon_{i j}$ - strain tensor, $\alpha$ - thermal expansion coefficient, $G, \lambda$ - Lamé parameters, $T$ - temperature, $T_{0}=10.5^{\circ} \mathrm{C}$ - reference temperature, which corresponds to zero thermal strain. The values adopted for the analysis are $G_{c}=14.237 \mathrm{GPa}, \lambda_{c}=$ $8.009 \mathrm{GPa}$ (corresponding to Young's modulus $E_{c}=$ $33.6 \mathrm{GPa}, v_{c}=0.18$ ) for concrete and $G_{s}=7.143 \mathrm{MPa}$, $\lambda_{s}=33.333 \mathrm{MPa}$ (equivalent to Young's modulus $E_{s}=$ $0.02 \mathrm{GPa}, v_{s}=0.4$ ) for subsoil. The concrete elasticity and strength parameters correspond to their average values determined from in-situ and laboratory tests conducted on the structure [9].

Boundary conditions are as follows. Oedometric boundary condition is prescribed to truncation surfaces of the subsoil region and expansion joints. In other words, displacements in the direction normal to surfaces are fixed and shear stress on the surfaces is 0 . Furthermore, the following loads are incorporated:

- dead weight of concrete and soil resulting from specific weight values equal to: $\gamma_{c}=24 \mathrm{kN} / \mathrm{m}^{3}$ and $\gamma_{s}=19 \mathrm{kN} / \mathrm{m}^{3}$ for concrete and subsoil, respectively;

- dead weight of the cranes, $Q_{c}=5242.5 \mathrm{kN}$;

- dead weight of the generating sets, $Q_{g s}=8662.7 \mathrm{kN}$ (each of two);

- operational load in offices and halls $q_{0}=5.0 \mathrm{kN} / \mathrm{m}^{2}$;

- traffic load on the bridge, $q_{t}=40.0 \mathrm{kN} / \mathrm{m}^{2}$;

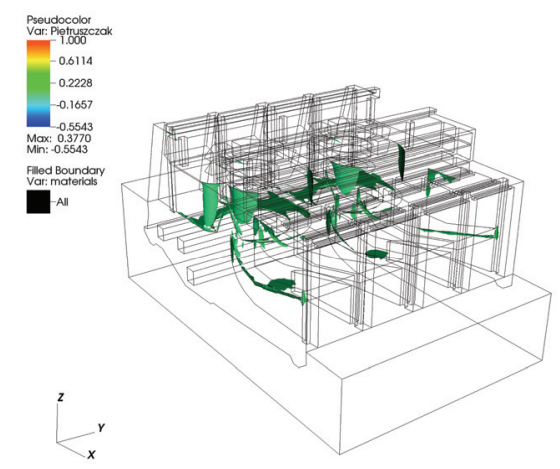

- pressure in draft tubes on the basis of calculation conducted with use of Flow3D FE code [9].

\section{RESULTS OF NUMERICAL ANALYSIS}

Because the aim of analysis is to evaluate strength state of the structure, a proper criterion for assessment needs to be chosen. A great number of failure criteria for concrete can be found in literature [10]-[13]. However, the one proposed by Pietruszczak et al. in [12] was chosen because it has a few advantages. It exhibits fair compatibility with experimental evidence and it is relatively simple in the mathematical form. The failure surface adopted in the analysis can be expressed as:

$$
f=a_{1} \frac{\sqrt{J_{2}}}{f_{c} g(\theta)}+a_{2}\left(\frac{\sqrt{J_{2}}}{f_{c} g(\theta)}\right)^{2}-\left(a_{3}+\frac{I}{f_{c}}\right)=0,
$$

where $a_{1}, a_{2}, a_{3}$ - dimensionless material constants, $f_{c}$ - uniaxial compressive strength of concrete; $I=\sigma_{k k}$ - first invariant of stress tensor; $J_{2}=1 / 2 s_{i j} s_{i j}$ - second invariant of stress deviator; $s_{i j}=\sigma_{i j}-1 / 3 \delta_{i j} \sigma_{k k}$, $\theta$ - Lode's angle, $g(\theta)$ - function determining the cross-section shape of limit surface in the deviatoric plane in the space of principal stresses. Within this analysis the following assumption applies: $g(\theta)=1.0$ $=$ const. Based on the research conducted by Pietruszczak et al. [12], the values of constants for concrete were adopted as follows: $a_{1}=1.9253, a_{2}=$ $0.5635, a_{3}=0.3$. The uniaxial compressive strength $f_{c}=30.0 \mathrm{MPa}$ corresponds to $\mathrm{C} 30 / 37$ class of concrete, which has been identified from in-situ measurements.

Figures 8-12 present the values of function $f$. To clarify the presentation of results, areas associated

Fig. 8. Non-negative values of failure function (4) for temperature distribution in November 

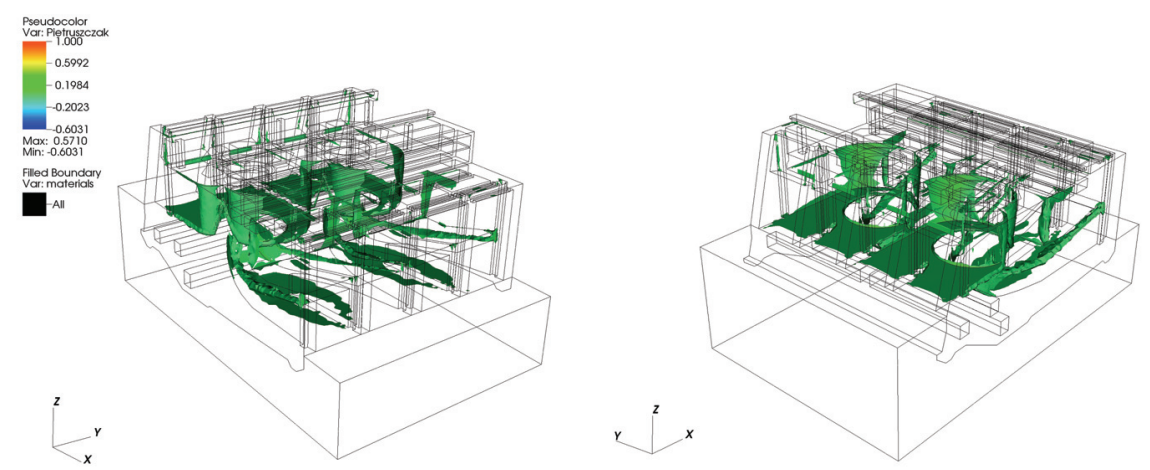

Fig. 9. Non-negative values of failure function (4) for temperature distribution in December

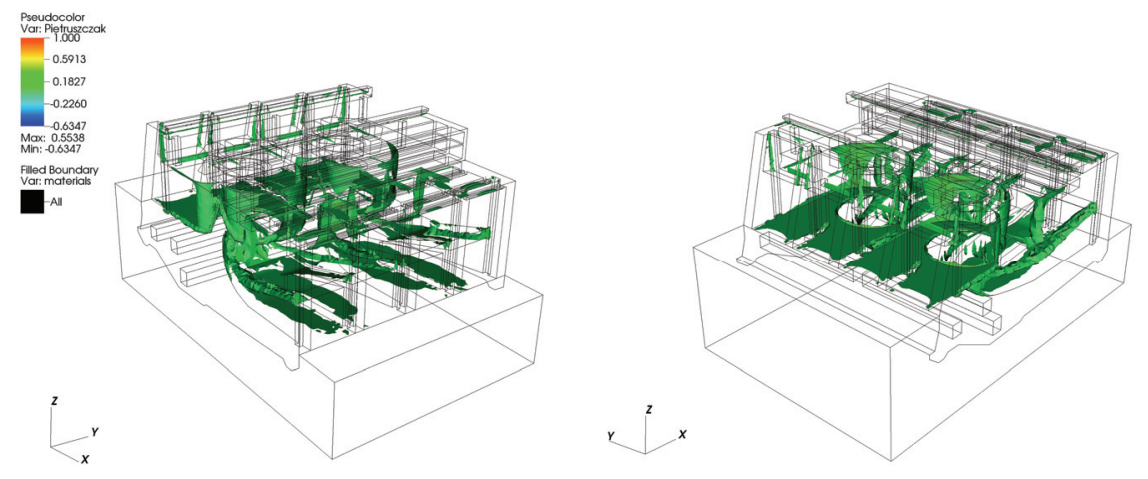

Fig. 10. Non-negative values of failure function (4) for temperature distribution in January

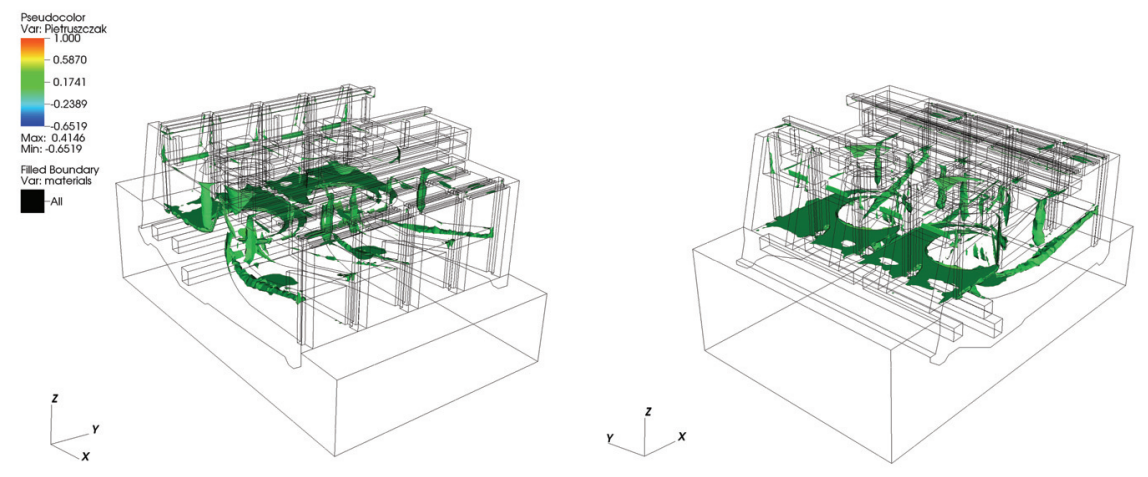

Fig. 11. Non-negative values of failure function (4) for temperature distribution in February
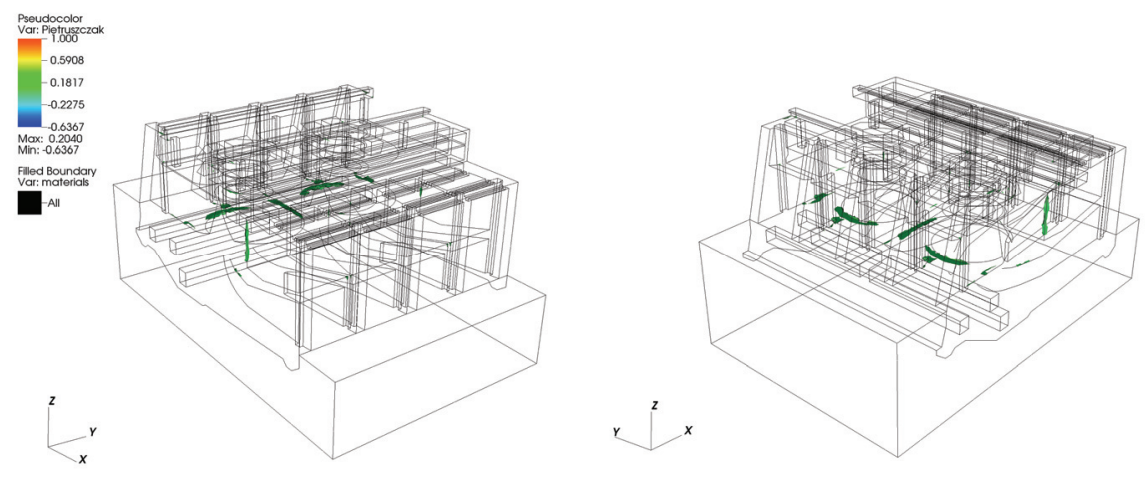

Fig. 12. Non-negative values of failure function (4) for temperature distribution in March 
with negative values of $f$ are set transparent. Thus, visible, colored subareas of the graphs indicate the space where the material strength was exceeded. The outcomes presented in these figures cover only the months for which the values exceeding zero appear within the domain, namely November-March.

The results obtained showed that exceeding of strength due to temperature effect occurs in winter months. The areas of draft tubes and spirals are notably affected. It is worth noting that the other mechanical loads accounted do not lead to damage without incorporating the temperature effect. Thus, the temperature effect is the crucial reason of exceeding of the safe stress level in the concrete.

\section{SUMMARY AND CONCLUSIONS}

The transient thermal-elasticity problem concerning HPP was solved. An assumption that mechanical properties do not depend on temperature state, justifies treating the problem as uncoupled. So the problem was solved in two stages. The first one involved the transient heat flow within the structure and extracted subsoil region. The second stage incorporated outcomes from the first one and evaluation of fields of mechanical quantities, i.e., displacement, stress and strain. The stress distributions calculated for different time points over the year were assessed based on failure criterion given in [12]. The effect of annual fluctuation in temperature was found to cause exceeding the strength of concrete elements. That confirms the findings from the former work of the authors [6]. The present analysis allows estimation of temperature effect at different time points over the year. Moreover, transient heat flow analysis and more sophisticated failure criterion for concrete result in outcomes that are more reliable.

The results presented indicate that the higher effort of concrete occurs in the winter months. Adverse temperature effect intensifies is January, when the exceeding of strength affects the largest subarea of the structure. The results are consistent with the observa- tions made on site: most of the cracks appeared in the area of draft tubes [9].

\section{REFERENCES}

[1] LÉGer P., TINAwi R., Mounzer N., Numerical simulation of concrete expansion in concrete dams affected by alkali-aggregate reaction: state-of-the-art, Canadian Journal of Civil Engineering, 1995, Vol. 22(4), 692-713.

[2] Li K., Coussy O., Numerical assessment and prediction method for the chemico-mechanical deterioration of ASRaffected concrete structures, Canadian Journal of Civil Engineering, 2004, Vol. 31(3), 432-439.

[3] AleKSANDROV Y.N., Analytical investigations of the performance of the dam at the Sayano-Shushenskaya HPP during an annual load cycle, Power Technology And Engineering - selective translations from gidrotekhnicheskoe stroitel'stvo and elektricheskie stantsii, 2006, Vol. 40, (No. 4), 224-228.

[4] De Schutter G., Finite element simulation of thermal cracking in massive hardening concrete elements using degree of hydration based material laws, Computers \& Structures, 2002, 80, 2035-2042.

[5] Parvini M., Pietruszczak S., Gocevski V., Seismic analysis of hydraulic structures affected by alkali-aggregate reaction: a case study, Canadian Journal of Civil Engineering, 2001, Vol. 28(2), 332-338.

[6] ŁyDŻBA D., RÓŻAŃSKI A., SOBÓTKA M., An annual cycle of changes in water temperature as a cause of cracking in massive concrete hydraulic structures, AGH Journal of Mining and Geoengineering, 2012, Vol. 36, No. 2, 217-227.

[7] Boley B.A., Weiner J.H., Theory of Thermal Stresses, Wiley, New York 1960, 586.

[8] ELzEIN A., A three-dimensional boundary element=Laplace transform solution of uncoupled transient thermo-elasticity in non-homogeneous rock media, Commun. Numer. Meth. Engng., 2001, 17, 639-646.

[9] ŁYDŻBA D. et al., Report No. 6/2011, “SPR” Series, Institute of Geotechnics and Hydrotechnics, Wroclaw University of Technology, 2011.

[10] ORTIZ M., A constitutive theory for the inelastic behavior of concrete, Mech. Mater., 1985, Vol. 4, (1), 67-93.

[11] KlisinSKi M., Mróz Z., Description of inelastic deformation and degradation of concrete, Int. J. Solids Struct., 1988, Vol. 24 (4), 391-416.

[12] Pietruszczak S., Jiang J., Mirza F.A., An elastoplastic constitutive model for concrete, International Journal of Solids and Structures, 1988, Vol. 24, Issue 7, 705-722.

[13] PietruszcZak S., XU G., Brittle response of concrete as a localization problem, International Journal of Solids and Structures, 1995, Vol. 32, 1517-1533. 